\title{
Determinação da capacidade suporte de trilhas do Parque Estadual Mata do Limoeiro, Itabira (MG), Brasil
}

O estudo da capacidade suporte de uma trilha é essencial para estimar o número de visitantes que o local comporta, além de ser possível analisar os prováveis impactos causados e mitigá-los. Dessa forma, o presente artigo teve como objetivo pesquisar e estudar a capacidade suporte das trilhas do Bosque; do Ribeirão; e do Sítio Jorge, as quais estão localizadas na Unidade de Conservação denominada Parque Estadual Mata do Limoeiro (PEML), no Distrito de Ipoema, Itabira - MG. Assim, a questão deste estudo é: quantos visitantes cada trilha analisada comporta por dia? A metodologia da pesquisa baseia-se na obra de Cifuentes (1992). Primeiramente, foi feito o reconhecimento das demandas das trilhas de acordo com o gestor e estas foram estudadas. Em seguida, os dados foram dispostos em tabela e realizaram-se cálculos e análises desses. Dessa forma, os resultados obtidos são que a Trilha do Bosque comporta 969 pessoas por dia; a Trilha do Ribeirão, 1034; e a Trilha do Sítio Jorge, 721. Em suma, a capacidade suporte adquirida em cada trilha indicia um número significativo em relação à quantidade de visitantes que o PEML recebe por dia atualmente, visto que o Parque foi criado recentemente. A capacidade suporte pode ser utilizada para favorecer o uso público de forma sustentável, não garantindo que obedecer somente à capacidade suporte da área fará com que a mesma mantenha-se preservada, sendo necessário promover a educação ambiental dos visitantes.

Palavras-chave: Unidades de Conservação; Ecoturismo; Uso Sustentável; Cifuentes.

\section{Determination of the support capacity of trails of Mata do Limoeiro State Park, Itabira (MG), Brazil}

\begin{abstract}
The study about supportability of an trail is essential to assess the number of visitors the area can receive, moreover it's possible to analyze the impacts caused and mitigate them. In this way, the article aims to research and study the supportability of the trials of Bosque, of Ribeirão and of Sítio Jorge; which are located in the Conservation Unit named Parque Estadual Mata do Limoeiro (PEML), in District of Ipoema, Itabira - MG. Therefore, the question is: how many visitors each trail analyzed can receive per day? The methodology of research was based on Cifuentes (1992). First, the manager recognized some demands of the trials and they were chosen and studied. After that, the data were disposed in tables, equations were solved and analyzed. By this way, the results obtained were that the Trail of Bosque admits 969 people per day; the Trail of Ribeirão, 1034; and the Trail of Sítio Jorge, 721. To conclude, the supportability obtained in each trail indicates a significant number based on the quantity of visitors PEML receives per day actually, since the Park was created recently. The supportability can be used to foment the public use in a sustainable way, not ensuring that follow this will preserve the area, so it is necessary the promotion of environmental education of the visitors.
\end{abstract}

Keywords: Conservation Unit; Ecoturism; Sustainable Use; Cifuentes.

Topic: Ecoturismo

Reviewed anonymously in the process of blind peer.

Isadora Figueiredo Monteiro Ferreira Universidade Federal de Itajubá, Brasil http://lattes.cnpq.br/1698375920605151 isadorafigueiredo94@gmail.com

Amanda Lopes Maciel

Universidade Federal de Itajubá, Brasil

http://lattes.cnpq.br/1501050983898119

amandamaciel.eng@gmail.com

Giuliana Camargo Vieira

Universidade Federal de Itajubá, Brasil

http://lattes.cnpq.br/8374335505111561

giulia.nah13@gmail.com
Received: 18/06/2016

Approved: 20/10/2016
Gabriel Martins de Medeiros

Universidade Federal de Itajubá, Brasil

http://lattes.cnpq.br/3513251434194432

gabrielmmedeiros1@gmail.com

Bianca Cabral Caldeira

Universidade Federal de Itajubá, Brasil

http://lattes.cnpq.br/9894812948681371

biancaunifei@gmail.com
Referencing this:

FERREIRA, I. F. M.; MACIEL, A. L.; VIEIRA, G. C.; MEDEIROS, G. M.; CALDEIRA, B. C.. Determinação da capacidade suporte de trilhas do Parque Estadual Mata do Limoeiro, Itabira (MG), Brasil. Nature and Conservation, v.9, n.1, p.13-26, 2016. DOI: http://doi.org/10.6008/SPC2318-2881.2016.001.0002 


\section{INTRODUÇÃO}

Uma Unidade de Conservação (UC) pode ser definida como um espaço territorial com características naturais relevantes e que tem a função de assegurar o uso sustentável de seus recursos naturais, preservando o patrimônio biológico existente. O Parque Estadual Mata do Limoeiro (PEML) está situado no distrito de Ipoema, no município de Itabira-MG, este possui uma área de 2.005,50 hectares e foi criado em 2011, protegendo importantes áreas de Cerrado e a Mata Atlântica (IEFP, 2011).

O uso público de uma Unidade de Conservação consiste em visitações com a finalidade de utilizar os recursos atrativos disponíveis e a infraestrutura presentes no local de forma turística, pedagógica, científica e incentivadora da conscientização ambiental. As visitações, com suas diversas finalidades são instrumentos importantes para aproximar os turistas e a população que vive no entorno da UC, e propagar a importância da conservação do meio ambiente e dos seus recursos naturais.

O Parque conta com um número significativo de atrativos que promovem a interação entre os visitantes e os moradores da região. Além disso, o PEML se tornou referência simultânea de lazer e preocupação ambiental para a população local. O Parque possui vários atrativos, como trilhas, cachoeiras, mirantes, entre outros. Dentre estes, vale mencionar as trilhas ecológicas do Bosque e do Ribeirão onde é possível contemplar a natureza bem como ter acesso ao ribeirão Macuco. Neste trajeto há também o Sítio Jorge, localidade na qual futuramente deseja-se implantar a casa do pesquisador com equipamentos laboratoriais que auxiliarão na execução de pesquisas em campo.

É importante destacar que a visitação a esses atrativos deve acontecer de forma consciente, respeitando a capacidade do local, pois todo ambiente possui um limite de uso que deve ser respeitado, para a conservação e o equilíbrio de seus recursos. O estudo presente busca tratar dos limites antrópicos de visitação na Trilha do Bosque, Trilha do Ribeirão e na Trilha que leva ao Sítio Jorge, a fim de preservar o que é de fato atrativo para os turistas, mantendo o potencial da experiência que a Unidade de Conservação pode promover a partir de seu uso público.

O planejamento da utilização dos recursos atrativos do Parque é importante para a proteção e preservação destes locais. Tal planejamento pode ser elaborado a partir da análise da capacidade suporte de cada atrativo citado acima, possibilitando uma utilização segura para os visitantes e dentro dos limites de suporte da área. Dessa forma o presente estudo tem por objetivo desenvolver os parâmetros e elaborar o cálculo da capacidade suporte das trilhas: do Bosque. Ribeirão e Sítio Jorge, situados no Parque Estadual Mata do Limoeiro em Itabira - MG.

\section{REVISÃO TEÓRICA}

O Sistema Nacional de Unidades de Conservação da Natureza (SNUC), Lei no 9.985/00, estabelece objetivos e categorias para Unidades de Conservação, as quais são definidas como sendo o "espaço territorial e seus recursos ambientais, incluindo as águas jurisdicionais, com características naturais relevantes, 
legalmente instituídos pelo Poder Público, com objetivos de conservação e limites definidos, sob regime especial de administração, ao qual se aplicam garantias adequadas de proteção" (BRASIL, 2000).

Esta lei tem por finalidade contribuir para a manutenção da diversidade biológica e dos recursos genéticos no território nacional e nas águas jurisdicionais, protegendo espécies ameaçadas de extinção, ecossistemas, paisagens naturais e características relevantes de natureza geológica, geomorfológica, espeleológica, arqueológica, paleontológica e cultural, recursos hídricos, edáficos e recursos naturais necessários à subsistência de populações tradicionais, respeitando e valorizando seu conhecimento e sua cultura e promovendo-as social e economicamente. Além dessas finalidades, o SNUC (BRASIL, 2002) também visa valorizar econômica e socialmente a diversidade biológica e proporcionar meios e incentivos para as atividades de pesquisa científica, estudos e monitoramentos ambientais.

O SNUC divide as UCs em duas categorias maiores, sendo elas Unidades de Proteção Integral e Unidades de Uso Sustentável. A primeira, Unidades de Proteção Integral, tem como objetivo a preservação da natureza, admitindo-se somente o uso indireto de seus recursos naturais, além de permitir atividades para pesquisas científicas, educação ambiental e turismo ecológico. Já a segunda, Unidades de Uso Sustentável, permite o uso sustentável de parte de seus recursos naturais unidos à conservação da natureza.

O uso público em Unidades de Conservação é definido no Plano de Manejo (PM) do local. Todas as categorias de manejo de UCs, com exceção das estações ecológicas e das reservas biológicas são passíveis de visitação pública, desde que observadas as regras contidas no Plano de Manejo e no Plano de Uso Público (PUP). Este último documento possui informações sobre como planejar e gerenciar a utilidade pública em Unidade de Conservação.

Para tanto, o PUP deve ser vinculado ao Plano de Manejo, de modo a evitar riscos e limitações (TAKAHASHI, 2004). Tendo em vista que a visitação às UCs tem aumentado muito nos últimos anos, em virtude da popularidade que o turismo ecológico vem alcançando, há a necessidade de se conciliar o uso público com a preservação da biodiversidade e demais recursos naturais encontrados nos espaços ambientais (LEUZINGER, 2006).

Conforme dados disponibilizados pelo Ministério do Meio Ambiente (MMA), atualizados em 26 de fevereiro de 2016, existe um total de 1979 UCs no Brasil (cobrindo cerca de $1.552 .769 \mathrm{~km}^{2}$ ), sendo 954 federais, 795 estaduais e 230 municipais. Destas, 609 são de Proteção Integral e 1.370 são de Uso Sustentável (CNUC/MMA, 2016).

A sustentabilidade das trilhas é possível ser alcançada mediante uma abordagem integrada de seu manejo, a partir dos objetivos traçados para a UC, considerando-se o planejamento, a construção, a manutenção, o monitoramento e a avaliação. O planejamento, por sua vez, deve observar não apenas os objetivos da Unidade, mas também os aspectos sociais e biofísicos da área, as oportunidades e restrições, as características dos usuários e a análise de sítio (LECHNER, 2006).

Com o objetivo de estimar o número máximo de visitantes que é suportado numa trilha, utiliza-se a metodologia da capacidade de carga. A ideia básica é estabelecer um número máximo de visitantes em uma determinada localidade, com o objetivo de minimizar os impactos provocados pela visitação. A metodologia 
base foi a de Cifuentes (1992), a qual é amplamente utilizada para determinar a capacidade de carga de determinado local, independente da área analisada.

\section{METODOLOGIA}

\section{Área de Estudo}

O Parque Estadual Mata do Limoeiro, criado pelo Decreto $n^{\circ} 45.566$, de 22 de março de 2011, e apresentando uma área de 2.005,50 hectares, situado no município de Itabira estado de Minas Gerais, é uma UC de Proteção Integral pertencente à categoria Parques representando 0,006\% da extensão territorial protegida por essa categoria, e 0,0013\% da área total de UCs do país (IEFP, 2011).

O PEML está localizado no Distrito de Ipoema, município de Itabira, distante aproximadamente 90 km da capital do estado, Belo Horizonte, e a 7 km do Parque Nacional Serra do Cipó, conforme a Figura 1. Em relação a outras capitais da região sudeste, Ipoema encontra-se a aproximadamente 672 km de São Paulo e a 550 km do Rio de Janeiro.

A criação da Unidade de Conservação Parque Estadual Mata do Limoeiro (PEML) visa à compensação ambiental pelos impactos causados por diversos empreendimentos minerários da Companhia Vale S.A. no município de Itabira, em atendimento as diretrizes do Sistema Nacional de Unidades de Conservação, que afirma na Resolução no 371/06:

[...] nos casos de licenciamento ambiental de empreendimentos de significativo impacto ambiental, assim considerado pelo órgão ambiental competente, com fundamento em estudo de impacto ambiental e respectivo relatório, o empreendedor é obrigado a apoiar a implantação e manutenção de unidade de conservação do Grupo de Proteção Integral, de acordo com o disposto neste artigo e regulamento desta Lei. (BRASIL, 2002)

A definição da área do Parque Estadual Mata do Limoeiro foi balizada pelo estudo desenvolvido por Delphi (2010), no qual foi analisada sua relevância para a conservação da biodiversidade, com vista à formalização do processo de criação da Unidade de Conservação Mata do Limoeiro. Seu limite territorial pode ser visualizado pela Figura 1, compreendendo entre os principais distritos da região rural.

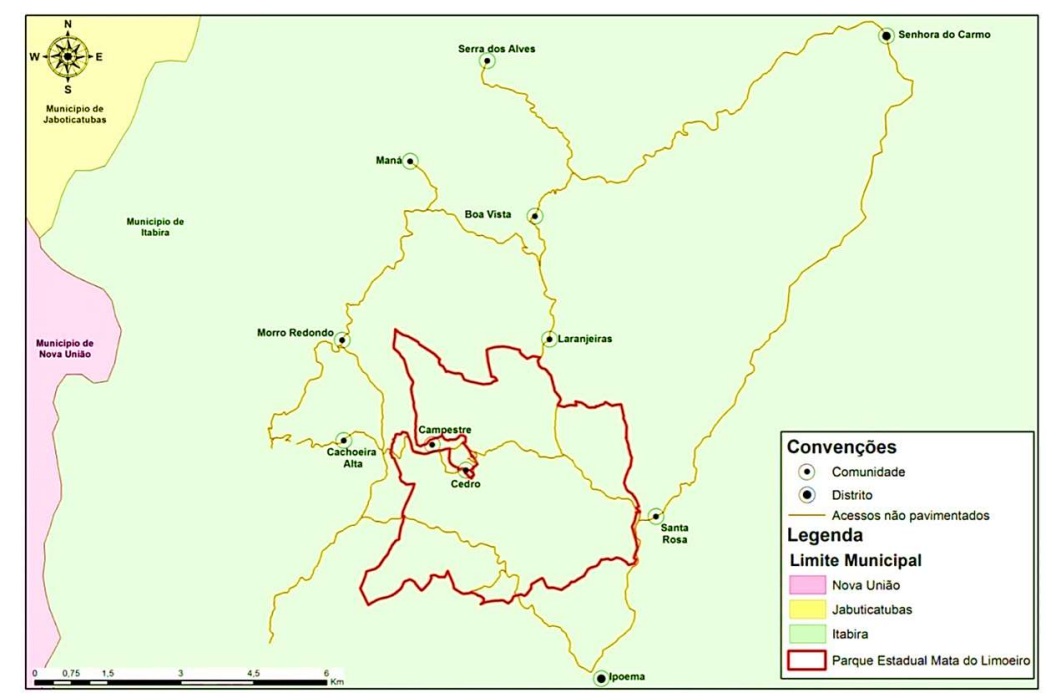

Figura 1: Limite territorial Parque Estadual Mata do Limoeiro.

Fonte: IEFP (2011) 
Para chegar ao local a partir de Ipoema, conta-se com linhas de ônibus que passam próximas ao Parque. E partindo de Belo Horizonte, deve-se seguir a BR 381 com sentido para João Monlevade, até entrar na cidade de Bom Jesus do Amparo. Após percorrer $6 \mathrm{~km}$ até a sede do município é possível visualizar placas que indicam o caminho até Ipoema, andando aproximadamente mais $15 \mathrm{~km}$ (PARQUES ESTADUAIS DE MINAS GERAIS, 2014).

O Parque possui grande diversidade biológica, pois se encontra em uma região onde há transição entre os biomas da Mata Atlântica e do Cerrado. Em relação à vegetação, sua principal fisionomia é de Floresta Estacional Semidecidual, e em menores proporções pode-se observar resquícios de Mata de Candeia e Várzeas (IEFP, 2011).

Já foram encontradas mais de 140 espécies de vegetais, sendo que duas delas, o jacarandá-caviúna e a braúna são classificadas como "vulneráveis", pela Fundação Biodiversidades e pelo Ministério do Meio Ambiente, ou seja, estas espécies estão ameaçadas de extinção. Em sua fauna, foram identificados 300 morfoespécies de insetos, 33 espécies de anfíbios, 18 espécies de répteis, 23 espécies de peixes, 40 espécies de mamíferos e 161 espécies de aves, sendo que 10 dessas espécies da fauna do Parque se encontram em risco de extinção (IEFP, 2011).

De acordo com a revista Parques Estaduais de Minas Gerais (2014), o PEML possui como atrações turísticas, as cachoeiras: do Derrubado, do Gabriel e do Paredão; a Cascata do Limoeiro; as lagoas do Sítio Jorge (e sua respectiva trilha) e do Limoeiro; os mirantes do Alto Campestre, do Campestre, do Lobo e da Mata do Segredo; a Gruta do Limoeiro; a trilha do Bosque; o Circuito Limoeiro Bike; e o Ribeirão Macuco e a respectiva trilha até o local. Destaca-se dos atrativos listados a Trilha do Bosque, a Trilha para chegar ao Ribeirão Macuco e a Trilha para o Sítio Jorge.

A Trilha do Bosque tem entrada próxima à portaria do Parque e é recomendada para qualquer pessoa, uma vez que seu grau de dificuldade é baixo. A Trilha do Ribeirão é contabilizada como o caminho percorrido após o final da Trilha do Bosque até o Ribeirão do Macuco. A Trilha para se chegar ao Sítio Jorge, em sua larga extensão, é reta e plana. Contudo, no fim desta não é possível visualizar o solo, pois há alta cobertura vegetal. Este fato pode dificultar a chegada ao Sítio. Todavia, há um planejamento de tornar o local uma casa para pesquisadores, e na ocorrência de tal fato, a trilha deverá ser modificada de modo a melhorar o acesso ao local (PARQUES ESTADUAIS DE MINAS GERAIS, 2014).

\section{Caracterização da Pesquisa}

O método adotado para o cálculo da capacidade de carga teve como base a metodologia proposta por Cifuentes (1992), e uma adaptação da mesma proposta por Cordeiro, Korossy e Selva (2013). De acordo com o estudo de Souza e Padovan (2007), este método apresenta fácil aplicação e adaptação a situações diversas, resultando em rapidez, eficiência e praticidade, desde que sejam levadas em conta as especificidades. Diante disto, os estudos voltados para o estabelecimento de capacidade de suporte objetivam estimar e indicar em termos quantitativos, o nível máximo permitido de exploração em certo sistema, de modo a não causar sua degradação. 
De acordo com Cifuentes (1992), o primeiro passo para determinar a capacidade de carga é estabelecer critérios e definir as variáveis físicas, ambientais e ecológicas, e de manejo que possam influenciar e limitar a quantidade de visitantes do atrativo.

Para tanto, o método empregado estabelece três níveis sucessivos de capacidade de carga: Capacidade de Carga Física (CCF); Capacidade de Carga Real (CCR); e Capacidade de Carga Efetiva (CCE), além da Capacidade de Manejo (CM).

\section{Cálculo da Capacidade de Carga Física (CCF)}

A primeira fase do cálculo (CCF) busca indicar quantos visitantes as trilhas do Bosque, Ribeirão e Sítio Jorge podem receber por dia, considerando as características biofísicas das mesmas. Assim, a Capacidade de Carga Física apresenta uma relação entre o espaço disponível para a visitação e o tempo em que o percurso realizado ocorre, sendo regida pela Equação 1:

$$
\mathrm{CCF}=\frac{\mathrm{S} . \mathrm{T}}{\mathrm{s} \cdot \mathrm{t}}
$$

(Equação 1)

$$
\begin{array}{r}
\text { Onde: } \\
\mathrm{S}=\text { superfície total da área visitada }\left(\mathrm{m}^{2}\right) ; \\
\mathrm{s}=\text { espaço ocupado por cada visitante }\left(\mathrm{m}^{2}\right) ;
\end{array}
$$

\section{Cálculo da Capacidade de Carga Real (CCR)}

Após a determinação, em parceria com o gestor do Parque Estadual Mata do Limoeiro, das trilhas que seriam estudadas, no dia 07 de novembro de 2015 foram levantados os pontos ao longo de todo o trecho percorrido que indicam obstáculos para que ocorram as visitações, os chamados fatores de correção.

Para o cálculo da Capacidade de Carga Real (CCR) das trilhas do Bosque, Ribeirão e Sítio Jorge, quatro Fatores de Correção $(\mathrm{FC})$ foram considerados: a acessibilidade $\left(\mathrm{FC}_{1}\right)$, alagamento $\left(\mathrm{FC}_{2}\right)$, cobertura vegetal $\left(\mathrm{FC}_{3}\right)$ e precipitação $\left(\mathrm{FC}_{4}\right)$. Isso se deve porque a acessibilidade mede o grau de dificuldade que os visitantes poderão encontrar durante o percurso da trilha. $O$ fator de correção alagamento se refere à quantidade de dias em um ano em que algum trecho das trilhas estudadas acumula água e dificulta a visitação. Justifica-se o fator de correção ausência de cobertura arbórea o fato de existirem alguns trechos da trilha que possuem uma maior fração solar em relação àqueles que têm presença da vegetação, fazendo com que, em algumas horas do dia, o brilho do sol seja maior e as visitas às trilhas sejam mais incômodas. Já o fator de correção precipitação limita a visitação na medida em que se considera que o período de chuvas pode chegar mesmo a cancelar os passeios.

Desse modo, foram calculados os Fatores de Correção, os quais são a forma de ajuste das variáveis relacionadas às características físicas, sociais, ambientais e biológicas, de visitação e de manejo do local e precisam ser consideradas na capacidade biofísica do espaço. O Fator de Correção (FC) é expresso da seguinte forma: 


$$
\mathrm{FC}=1-\frac{\mathrm{Ml}}{\mathrm{Mt}}
$$

(Equação 2)

$$
\text { Mt = Magnitude total. }
$$

Uma vez calculados todos os Fatores de Correção, a CCR é expressa por meio da seguinte fórmula:

$$
\mathrm{CCR}=\mathrm{CCF} \times \mathrm{FC}_{1} \times \mathrm{FC}_{2} \times \ldots \times \mathrm{FC}_{\mathrm{n}}
$$

(Equação 3)

Onde:

CCF = Capacidade de Carga Física; $\mathrm{FC}_{1}=$ Fator de Correção da variável 1; $\mathrm{FC}_{2}=$ Fator de Correção da variável 2; e $\mathrm{FC}_{\mathrm{n}}=$ Fator de Correção da variável " $n$ ".

\section{Cálculo da Capacidade de Manejo (CM)}

A capacidade de manejo representa o percentual de estado da trilha em relação à administração da mesma como um atrativo de uma Unidade de Conservação, consistindo assim, uma análise necessária para a determinação da capacidade de carga antrópica da cada trilha. É definido como o melhor estado ou condição que a administração de uma área protegida deve ter para desenvolver suas atividades e alcançar seus objetivos (CIFUENTES, 1992).

No caso das trilhas analisadas do Parque Estadual Mata do Limoeiro, para se realizar o cálculo da Capacidade de Manejo, foram consideradas as variáveis pessoais infraestrutura e equipamentos, por abordarem uma série de componentes de fácil análise e medição, as quais serão detalhadas mais adiante.

De acordo com o método Cifuentes (1999) adaptado, cada variável deve ser valorizada da seguinte forma:

$$
\mathrm{CM}=\frac{\mathrm{Qe}}{\mathrm{Qs}}
$$

$$
\text { (Equação 4) }
$$

Onde:

$\mathrm{CM}=$ Capacidade de Manejo;

Qe = quantidade existente de uma determinada variável; e Qs = quantidade que deveria ter de acordo com as necessidades ao longo de todo o trecho da trilha percorrida.

Esta relação representa o percentual entre a quantidade existente e a ideal para a funcionalidade, tanto para os funcionários como para os visitantes, da distribuição espacial adequada dos componentes da área, assim como a facilidade de acesso aos mesmos.

\section{Cálculo da Carga Efetiva (CCE)}


Assim, a última etapa do processo de cálculo a partir do método de Cifuentes é a estimativa da Capacidade de Carga Efetiva (CCE), e é entendida como o limite máximo admissível de pessoas numa área, considerando-se a capacidade do órgão gestor para ordenar e manejar estas pessoas. A CCE é definida por meio da fórmula:

$$
\mathrm{CCE}=\mathrm{CCR} \times \mathrm{CM}
$$

(Equação 5)

Onde: CCR = Capacidade de Carga Real; e $\mathrm{CM}=$ Capacidade de Manejo (\%).

Em suma, a metodologia da Capacidade de Carga de Cifuentes (1992) pode ser definida da seguinte forma: por meio de fatores como a avaliação da área disponível, de variáveis relacionadas à visita e ao espaço ocupado por cada visitante, obtém-se a Capacidade de Carga Física da área. Da união desta com os Fatores de Correção, os quais quantificam variáveis relativas às fragilidades ambientais, obtém-se a Capacidade de Carga Real. Seguido disto, obtém-se a Capacidade de Carga Efetiva por meio da relação entre Capacidade de Manejo e da Capacidade de Carga Relativa. Analisando as relações utilizadas, percebe-se que cada uma representa uma capacidade corrigida em relação à anterior, devido a isto, a Capacidade de Carga Física é sempre maior que a Capacidade de Carga Relativa, a qual pode ser maior ou igual à Capacidade de Carga Efetiva (SILES, 2003).

É importante salientar que as trilhas são sequenciais, dispostas na seguinte ordem: 1a) Trilha do Bosque; 2a) Trilha do Ribeirão; 3a) Trilha Sítio Jorge; ou seja, para chegar à Trilha Sítio Jorge é preciso passar anteriormente pela Trilha do Bosque e pela Trilha do Ribeirão, da mesma forma que para chegar à Trilha do Ribeirão passa-se anteriormente pela Trilha do Bosque. No presente estudo consideraram-se os limites de cada trilha a partir do final oficial da anterior, por exemplo, a Trilha do Ribeirão, é contada a partir do final da Trilha do Bosque até o início da Trilha Sítio Jorge e a Trilha Sítio Jorge foi considerada a partir da Trilha do Ribeirão até a sede do Sítio Jorge.

\section{RESULTADOS E DISCUSSÕES}

Nessa seção serão apresentados os resultados de capacidade de suporte obtido para a Trilha do Bosque, a Trilha do Ribeirão e a Trilha Sítio Jorge, respectivamente. O mapa que apresenta o trajeto das trilhas (sabendo-se que uma é continuação da outra) encontra-se disponível no Apêndice, ao final deste trabalho.

\section{Trilha do Bosque}

Considerou-se a Capacidade de Carga Física, a Capacidade de Carga Real e por fim Capacidade de Carga Efetiva, para definir o número de pessoas máximo suportado pela Trilha do Bosque, por dia.

\section{Capacidade de Carga Física}


Para realizar o cálculo da capacidade de carga física utilizou-se a Equação 1. A área da trilha foi obtida por meio de medições em campo, o tempo total que a área estava aberta à visitação foi informado pelos funcionários do Parque. Adotou-se o espaço ocupado por cada visitante como sendo de $1 \mathrm{~m}^{2}$ e o tempo necessário para visitar a área foi o tempo de ida e volta, levando em consideração uma trilha interativa, onde o visitante pudesse obter informações das espécies existentes e desfrutar dos atrativos ao longo da trilha. Dessa forma, os dados utilizados na Equação 1 foram: (a) Área da trilha: 622,91 m²; (b) Tempo total para visitar a área: 8 h; (c) espaço ocupado por cada visitante: $1 \mathrm{~m}^{2}$; (d) Tempo necessário para visitar a área: 30 min. Com isso, tem-se o CCF $=10606$ pessoas/dia.

\section{Capacidade de Carga Real}

O primeiro Fator de Correção considerado foi a acessibilidade. Segundo Correia (2014), declividades inferiores a 15\% não apresentam riscos ao visitante. Para o cálculo das declividades mediu-se em campo com o GPS a diferença das cotas dos trechos em aclive ou declive e com a trena, a distância inclinada entre esses trechos. Com essas informações obteve-se por Pitágoras a distância horizontal entre os pontos iniciais e finais dos trechos em aclive e declive e calculou-se a declividade desses pontos a partir das diferenças de cotas e a distância horizontal obtida.

Assim, a magnitude limitante $\left(\mathrm{ML}_{1}\right)$ considerada nesse fator de correção foi o comprimento horizontal inclinado dos trechos com declividade maior que 15\%. E para a magnitude total $\left(\mathrm{MT}_{1}\right)$, foi adotado o comprimento total da trilha. Utilizando $\mathrm{ML}_{1}=76,31 \mathrm{~m}$ e $\mathrm{MT}_{1}=301,95 \mathrm{~m}$, foi possível o cálculo do fator de correção pela Equação 2, obtendo $\mathrm{FC}_{1}=0,7473$.

O Fator de Correção alagamento $\left(\mathrm{FC}_{2}\right)$ foi realizado considerando a magnitude limitante como o número de dias do ano em que a trilha se encontrava alagada e a magnitude total como o total de dias do ano. Diferente das trilhas que serão analisadas a seguir, a Trilha do Bosque não apresenta alagamento ao longo do ano, por isso esse fator de correção não foi relevante na análise dessa trilha, sendo igual a 1 (um).

Para a determinação do Fator de Correção ausência de cobertura arbórea $\left(\mathrm{FC}_{3}\right)$, considerou-se como magnitude limitante a área na qual havia ausência de cobertura arbórea sobre o trecho da trilha $\left(\mathrm{ML}_{3}=\right.$ 231,99 $\mathrm{m}^{2}$ ), e como magnitude total adotou-se a área total da trilha $\left(\mathrm{MT}_{3}=662,91 \mathrm{~m}^{2}\right)$. Logo, $\mathrm{FC}_{3}=0,6500$.

Para a análise do Fator de Correção precipitação $\left(\mathrm{FC}_{4}\right)$ adotou-se como magnitude limitante o período de maior ocorrência de chuvas e como magnitude total $\left(\mathrm{MT}_{4}=12\right.$ meses). Analisando os dados de precipitação de Ipoema (MG), observou-se que o período de maior precipitação se encontra entre outubro e março, adotando-se dessa forma 6 (seis) meses como o período chuvoso (CLIMATE-DATA, 2015), sendo $\mathrm{ML}_{4}=6$ meses. É importante salientar que não apenas os dias de fato com ocorrência de precipitação limitam a visitação, mas também dias com ameaças de chuva são responsáveis por desestimular os visitantes. Outro fator a se considerar é que por esse cálculo subentende-se que não ocorre precipitação em 6 (seis) meses do ano, o que não condiz com a realidade, porém esses dias são compensados pelos dias contabilizados nos 6 (seis) meses de precipitação, uma vez que nem todos os dias dos 6 (seis) meses de precipitação considerados têm chuva, ou mesmo ameaça de chuva. Logo, o Fator de Correção $\left(\mathrm{FC}_{4}\right)$ da precipitação é de 0,5000. 
O cálculo da Capacidade de Carga Real, considerando os Fatores de Correção anteriormente descritos, foi realizado por meio da Equação 3 e obteve-se CCR $=2576$ pessoas/pessoas/dia.

\section{Capacidade de Carga Efetiva}

Para o cálculo da Capacidade de Carga Efetiva é necessário levantar a capacidade de manejo da área de estudo, para isso, levantou-se as informações disponíveis da Tabela 1, que são relativas à infraestrutura do parque como um todo. Os dados específicos da Trilha do Bosque estão disponíveis na Tabela 2.

Tabela 1: Capacidade de Manejo do Parque Estadual Mata do Limoeiro.

\begin{tabular}{l|l|l}
\hline Estrutura & Capacidade Instalada & Capacidade Ideal \\
\hline Mirantes & 1 & 5 \\
\hline Carros para fiscalização & 3 & 5 \\
\hline Motos para fiscalização & 1 & 4 \\
\hline Prédio administrativo & 1 & 1 \\
\hline Gestor & 1 & 1 \\
\hline Monitores & 1 & 4 \\
\hline Zelador ambiental & 5 & 8 \\
\hline Capacitação anual de monitores (anual) & 0 & 2 \\
\hline Equipamentos de radiocomunicação & 7 & 15 \\
\hline Manutenção da infraestrutura (anual) & 0 & 6 \\
\hline Equipe de poda & 0 & 5 \\
\hline Brigadistas & 6 & 20 \\
\hline Quite de EPI por pessoa & 1 & 1 \\
\hline Posto Policial & 0 & 1 \\
\hline
\end{tabular}

Tabela 2: Capacidade de Manejo da Trilha do Bosque.

\begin{tabular}{c|c|c}
\hline Estrutura & Capacidade Instalada & Capacidade Ideal \\
\hline Bancos & 1 & 1 \\
\hline Ponte & 1 & 1 \\
\hline Placas Sinalizadoras & 3 & 5 \\
\hline
\end{tabular}

A Capacidade de Manejo total obtida foi de 37,65\% para o conjunto infraestrutura do Parque e Trilha do Bosque. A partir dessas informações foi possível calcular a capacidade de carga efetiva da Trilha do Bosque. Utilizando a Equação 5 e CCR $=2576$ e CM $=37,65 \%$, obteve-se CCE $=969$ pessoas $/$ dia. As capacidades suporte calculadas nos tópicos a seguir utilizaram o mesmo procedimento descrito nesse tópico, obedecendo ao mesmo processo em campo descrito nesse item.

\section{Trilha do Ribeirão}

Considerou-se a Capacidade de Carga Física, a Capacidade de Carga Real e por fim Capacidade de Carga Efetiva, para definir o número de pessoas máximo suportado pela Trilha do Ribeirão, por dia.

\section{Capacidade de Carga Física}

Calculou-se a capacidade de carga física por meio da Equação 1, utilizando os seguintes dados obtidos: (a) Área da trilha: 1183,25 m²; (b) Tempo total para visitar a área: 8 h; (c) espaço ocupado por cada visitante: $1 \mathrm{~m}^{2}$; (d) Tempo necessário para visitar a área: $50 \mathrm{~min}$. Assim, obteve-se CCF = 11363 pessoas/dia. 


\section{Capacidade de Carga Real}

Para o cálculo dos Fatores de Correção foi utilizada a Equação 2.

Fator de Correção acessibilidade: $\mathrm{ML}_{1}=47,8 \mathrm{~m}$ e $\mathrm{MT}_{1}=549,02$

$$
\mathrm{FC}_{1}=0,9130 \text {. }
$$

Fator de Correção alagamento: $\mathrm{ML}_{2}=45$ e $\mathrm{MT}_{2}=365$

$$
\mathrm{FC}_{2}=0,8767 \text {. }
$$

Fator de Correção ausência de cobertura arbórea: $M L=346,75 \mathrm{~m}^{2}$ e $\mathrm{MT}=1183,45 \mathrm{~m}^{2}$,

$$
\mathrm{FC}_{3}=0,7070 \text {. }
$$

Fator de Correção precipitação: ML = 6 e MT = 12

$$
\mathrm{FC}_{4}=0,5000 \text {. }
$$

A Capacidade de Carga Real da trilha do Ribeirão foi calculada utilizando-se os Fatores de Correção levantados, por meio da Equação 3, e obteve-se CCR = 3215 pessoas/dia.

\section{Capacidade de Carga Efetiva}

A Capacidade de Carga efetiva foi realizada utilizando as informações referentes à Capacidade de Manejo da infraestrutura do Parque como um todo (Tabela 1), e as informações referentes a Trilha do Ribeirão (Tabela 3), por meio da Equação 4.

Tabela 3: Capacidade de Manejo da Trilha do Ribeirão.

\begin{tabular}{c|c|c}
\hline Estrutura & Capacidade Instalada & Capacidade Ideal \\
\hline Placas Sinalizadoras & 1 & 7 \\
\hline Ponte & 0 & 1 \\
\hline Bancos & 0 & 1 \\
\hline
\end{tabular}

Contabilizando as informações da Tabela 1 e da Tabela 3, obteve-se uma Capacidade de Manejo de $32,18 \%$. Logo, CCE $=1034$ pessoas/dia.

\section{Trilha Sítio Jorge}

Considerou-se a Capacidade de Carga Física, a Capacidade de Carga Real, e por fim Capacidade de Carga Efetiva, para definir o número de pessoas máximo suportado pela Trilha Sítio Jorge, por dia.

\section{Capacidade de Carga Física}

A Capacidade de Carga Física da Trilha Sítio Jorge foi realizada utilizando-se a Equação 1 e os dados a seguir: (a) Área da trilha: 2249,28 m²; (b) Tempo total para visitar a área: 8 h; (c) espaço ocupado por cada visitante: $1 \mathrm{~m}^{2}$; (d) Tempo necessário para visitar a área: $1 \mathrm{~h} 40 \mathrm{~m}$. Com isso, obteve-se CCF $=10775$ pessoas/dia.

\section{Capacidade de Carga Real}

Para o cálculo dos Fatores de Correção utilizou-se a Equação 2. 
Fator de Correção acessibilidade: $\mathrm{ML}_{1}=160,71 \mathrm{~m}$ e $\mathrm{MT}_{1}=1614,25 \mathrm{~m}$

$$
\mathrm{FC}_{1}=0,9004 \text {. }
$$

Fator de Correção alagamento: $\mathrm{ML}_{2}=45$ e $\mathrm{MT}_{2}=365$

$$
\mathrm{FC}_{2}=0,8767 \text {. }
$$

Fator de Correção ausência cobertura arbórea: $\mathrm{ML}_{3}=1140,63 \mathrm{~m}^{2}$ e $\mathrm{MT}_{3}=2249,28 \mathrm{~m}^{2}$

$$
\mathrm{FC}_{3}=0,4929 \text {. }
$$

Fator de Correção precipitação: $\mathrm{ML}_{4}=6$ e $\mathrm{MT}_{4}=12$

$$
\mathrm{FC}_{4}=0,5000 \text {. }
$$

Com as informações levantadas dos Fatores de Correção foi possível calcular a Capacidade de Carga Real, por meio da Equação 3, e obteve-se CCR = 2096 pessoas/dia.

\section{Capacidade de Carga Efetiva}

A Capacidade de Carga Efetiva foi obtida considerando-se a capacidade de manejo da área em estudo (Tabela 1), mais as especificidades da Trilha Sítio Jorge (Tabela 4), por meio da Equação 5.

Tabela 4: Capacidade de Manejo da Trilha Sítio Jorge.

\begin{tabular}{c|c|c}
\hline Estrutura & Capacidade Instalada & Capacidade Ideal \\
\hline Placas Sinalizadoras & 4 & 10 \\
\hline Bancos & 0 & 2 \\
\hline
\end{tabular}

Por meio dos dados disponíveis na Tabela 1 e na Tabela 4, obteve-se a Capacidade de Manejo de $34,44 \%$ e, portanto, CCE $=722$ pessoas/dia.

\section{Síntese das Capacidades Suporte Obtidas}

As capacidades suportes encontradas nas Trilhas em estudo estão sintetizadas na Tabela 5.

Tabela 5: Capacidade de Suporte das Trilhas Analisadas.

\begin{tabular}{c|c}
\hline Atrativo & Capacidade de Suporte \\
\hline Trilha do Bosque & 969 pessoas/dia \\
\hline Trilha do Ribeirão & 1034 pessoas/dia \\
\hline Trilha Sítio Jorge & 722 pessoas/dia \\
\hline
\end{tabular}

É importante destacar que a Trilha do Bosque é um caminho para a Trilha do Ribeirão, e mesmo que a Trilha do Bosque apresente uma capacidade suporte menor que a Trilha do Ribeirão existe uma passagem alternativa para a mesma, de modo que é possível o número máximo de pessoas definido na capacidade e suporte visitar a Trilha do Ribeirão, sem ultrapassar a capacidade suporte da Trilha do Bosque.

As capacidades suporte encontradas são de fundamental importância para que o uso público aconteça de forma adequada, respeitando as capacidades suportadas por cada trilha, aliando de forma consciente as atividades turísticas, educacionais e educativas com a preservação dos recursos naturais. Atualmente as capacidades suporte são respeitadas para todas as trilhas, visto que a criação do Parque é recente e o mesmo ainda não recebe números grandes de visitantes como as capacidades suporte máximas 
estabelecidas. O presente estudo apresenta uma contribuição e uma projeção para a regulamentação de visitações futuras, devido ao potencial turístico da área em estudo.

\section{CONSIDERAÇÕES FINAIS}

A determinação da capacidade suporte de uma localidade é de extrema importância uma vez que adequa o uso do recurso com as capacidades suportadas pelo mesmo. Quando essa análise é feita em um Parque Estadual, como é o caso do presente estudo, esta se faz ainda mais necessária, visto que o uso público faz parte das atribuições que devem ser atendidas pela Unidade de Conservação.

Conforme abordado no Plano de Manejo do Parque Estadual Mata do Limoeiro, nenhum dos atrativos identificados possui qualquer infraestrutura de apoio, o que torna o ecoturismo pouco manejado. Neste sentido, cabe ressaltar que anteriormente à implantação da visitação, todas as trilhas necessitarão de intervenções minuciosas com objetivo de conservar a integridade do ambiente. Uma das maneiras de implementar essa conservação é por meio de capacidades de suportes que visam assegurar o uso sustentável dos recursos naturais.

Dessa forma os valores de capacidades suportes encontrados para a Trilha do Bosque de 969 pessoas/dia, para a Trilha do Ribeirão de 1034 pessoas/dia e para a Trilha Sítio Jorge de 721 pessoas/dia, são de fundamental importância para direcionar o uso adequado desses atrativos, conciliando a visitação ao Parque Estadual Mata do Limoeiro com as capacidades suportadas pelas trilhas, promovendo o uso público de forma sustentável. Destaca-se ainda que simplesmente obedecer às capacidades suporte estabelecidas não é garantia de preservação da área, é necessário conscientização e educação ambiental para que de fato os recursos naturais sejam protegidos.

\section{REFERÊNCIAS}

BRASIL. Lei n.9985 de 18 de julho de 2000. Decreto n.4340 de 22 de agosto de 2002. Dispõe sobre o Sistema Nacional de Unidades de Conservação (SNUC). Brasília: MMA/SBF, 2002.

BOGGIANI, P. C.; SILVA, O. J.; GESICKI, A. L. D.; GALLATI, E. A. B.; SALLES, L. O.; LIMA, M. M. E. R.. Definição de capacidade de carga turística das cavernas do Monumento Natural Gruta do Lago Azul (Bonito, MS). Geociências, São Paulo, v.26, n.4, p.333-348, 2007.

CIFUENTES, M.. Determinacion de Capacidad de Carga Turistica em Areas Protegidas. Série Técnica: Informe Técnico, n.194. Costa Rica: CATIE, 1992.

CLIMATE-DATA. Clima: Ipoema (Distrito de Itabira). 2015.

CNUC/MMA. Cadastro Nacional de Unidades de Conservação/Ministério do Meio Ambiente. 2016. Tabela consolidada das Unidades de Conservação. Brasília: MMA, 2016.

CORREIA, B. H.. Trilha do bolonha: análise da capacidade de carga turística como ferramenta de desenvolvimento turístico e uso racional de espaços públicos naturais em área urbana. In: CONGRESSO BRASILEIRO DE GESTÃO AMBIENTAL, 5. Anais. Belo Horizonte: Ibeas, 2014.

CORDEIRO, I. D.; KÖRÖSSY, N.; SELVA, V.. Determinação da capacidade de carga turística a partir do método CIFUENTES ET AL. (1992): aplicação à Praia dos Carneiros (tamandaré/PE). Revista Turismo Visão e Ação, v.15, n.1, p.57-70, 2013.

DELPHI PROJETOS E GESTÃO. Estudo Técnico para Formalização do Processo de Criação da Unidade de Conservação Mata do Limoeiro, Itabira, MG. Relatório Técnico. 2010.

LECHNER, L.. Planejamento, implantação e manejo de trilhas em unidades de conservação. Cadernos de Conservação, v.3, n.3, 2006.

LEUZINGER, M. D.. Uso público em unidades de conservação. 2006.

PARQUES ESTADUAIS DE MINAS GERAIS. São Paulo: Horizonte, 2014 
IEFP. Plano de Manejo do Parque Estadual Mata do

Limoeiro. Palmas: Instituto Estadual de Florestas. Palmas. 2011.

SILES, M. F. R.. Modelagem especial para atividades de visitação pública em áreas naturais. São Paulo: IOB/USP, 2003.
SOUZA, W.; PADOVAN, M. P.. Análise da aplicação das metodologias de avaliação da capacidade de carga nas unidades de conservação brasileiras. In: CONGRESSO BRASILEIRO DE UNIDADES DE CONSERVAÇÃO, 5. Anais. Foz do Iguaçu, 2007.

TAKAHASHI, L.. Uso público em unidades de conservação. Cadernos de Conservação, v.2, n.2, 2004. 